\title{
PLANKTON BIODIVERSITY OF THE NORTH ATLANTIC: CHANGING PATTERNS REVEALED BY THE CONTINUOUS PLANKTON RECORDER SURVEY.
}

\author{
P H Burkill ${ }^{(1)} \&$ P C Reid $^{(2)}$ \\ (1) Sir Alister Hardy Foundation for Ocean Science, Citadel Hill, Plymouth PL1 2PB, UK \& Marine Institute, \\ University of Plymouth, Drake Circus, Plymouth PL4 8AA, UK, Email: phb@sahfos.ac.uk \\ (2) Sir Alister Hardy Foundation for Ocean Science, Citadel Hill, Plymouth PL1 2PB, UK \& Marine Institute, \\ University of Plymouth, Drake Circus, Plymouth PL4 8AA, UK. Email: pcre@sahfos.ac.uk
}

\begin{abstract}
The Continuous Plankton Recorder Survey operates across northern ocean basins where it has generated definitive datasets on decadal scale changes in plankton biodiversity. The survey has shown biological, environmental and climatic indicators that relate to global change impacts within marine ecosystems. In the last decade, the survey has demonstrated major alteration within Atlantic plankton communities including the northerly displacement of communities by $\sim 1,000 \mathrm{~km}$. Regime shifts have been identified with sensitivity to a $10^{\circ} \mathrm{C}$ isotherm with similar responses across multiple trophic levels. Such behaviour of plankton ecosystems offers a method of prediction the locations of future communities. The survey has also shown transfer of Pacific phytoplankton in to the Atlantic for the first time in 800,000 years with unknown consequences for the native ecosystem. Understanding global issues requires a global approach and a future cooperative commonwealth of regional plankton biodiversity surveys is proposed that links current surveys with proposed new surveys.
\end{abstract}

\section{INTRODUCTION}

The Continuous Plankton Recorder Survey is the longest (starting in 1931), most geographically extensive (pan Atlantic and other ocean basins) marine biological survey in the world with a unique dataset of marine biodiversity (500 taxa). It has generated over 1,000 peer reviewed papers on various aspects of biological, environmental and climatic indicators particularly on impacts of global anthropogenic change on marine ecosystems.

This paper celebrates some of the past scientific discoveries of the Continuous Plankton Recorder (CPR) Survey operated by the Sir Alister Hardy Foundation for Ocean Science (www.sahfos.ac.uk) in Plymouth, UK. Future activities of the Survey are identified in [9].
Although the CPR Survey operates in all the major ocean basins except the Indian Ocean, it severely undersamples the plankton in all basins compared say to the global coverage achieved for ocean color or even Argo (Array for Real-time Geostrophic Oceanography). An exception is the North Atlantic where the CPR Survey has operated since 1931. For this reason, the success stories focus on the North Atlantic. At the end of the paper, we advocate that a global survey needs to be generated and the first steps that are being taken to achieve this.

\subsection{Why study plankton biodiversity?}

Understanding plankton biodiversity in our oceans is essential for three main reasons.

Firstly, life originated in the ocean some four thousand million year ago and today all but one of the major taxonomic phyla currently live there. The evolutionarily simplest, and indeed the most numerous, life forms in the oceans are the plankton, a taxonomically heterogeneous group of microscopic plants (phytoplankton), animals (zooplankton) and microbes (bacteria, archaea and viruses). Plankton are found throughout the $1.5 \times 10^{9} \mathrm{~km}^{3}$ living space of the world's ocean making them the most ubiquitous life form on Earth. An understanding of plankton is a key component to understanding of life on our planet.

Secondly, the ocean's foodweb depends crucially upon plankton, since these simple primary and secondary producers form the functional base of all marine ecosystems. The totality of the ocean's primary production estimated to be some $48 \times 10^{15}$ tonnes C annually [1]. This activity carried out by microscopic phytoplankton is transferred via zooplankton to fuel the global production of 240 million metric tonnes of fish. Of this some 80 million metric tonnes of fish is harvested annually by fishing activity. 
Third, but by no means least, plankton play a crucial role with their interaction with our climate. This interaction is a two-way process. On the one hand, plankton are responsible for some $46 \%$ of the planetary photosynthesis. This process, which involves the assimilation of $\mathrm{CO}_{2}$ and its transformation into organic material, results in the reduction of ambient $\mathrm{CO}_{2}$. This is the first step in a series of complex biogeochemical transformations, termed the biological pump that involves the export of carbon and other elements from atmosphere and surface waters into the oceans interior. The waters of the ocean's interior are out of contact with the atmosphere and therefore the carbon is in a transient sink so far as climate is concerned. The typical time scale of the turnover of this transient sink is in the order of a few thousands of years. However, the role of plankton in climate control extends much further than the reduction of atmospheric carbon dioxide. Some common plankton taxa, typically coccolithophores and dinoflagellates, produce dimethyl sulfonioproprionate (DMSP). DMSP is converted to dimethyl sulphide (DMS) a volatile compound that is important in cloud formation over the ocean, via biogeochemical transformations involving viruses, bacteria, archaea, protozoa and metazoa in the surface ocean. This remains an active and controversial research field of how plankton communities may be able to create their own atmospheric weather

On the other hand, plankton are also strongly influenced by climatic and other environmental forcing processes. These include changes in temperature, $\mathrm{pH}$, sunlight, current speed and direction, water-mixing as well as innate changes in the properties of the marine foodweb.

\subsection{The Continuous Plankton Recorder Survey}

The Continuous Plankton Recorder (CPR) survey is the only biological monitoring programme that operates on an ocean basin scale with monthly sampling over decadal time scales. Merchant ships voluntarily tow CPRs, at a depth of $\sim 10 \mathrm{~m}$, on their normal routes of passage in the Atlantic, Pacific, Arctic and Southern Oceans. The survey is unique in that the methodology and plankton analysis procedures for 500 taxa have been maintained with little change for more than 70 years [2].

\section{DECADAL CHANGES IN PLANKTON BIODIVERSITY}

The broad temporal and spatial scales upon which the CPR Survey operates offers a unique insight into how the plankton communities are changing. Some of recent scientific discoveries from the north Atlantic survey are presented below.

\subsection{First hints of contemporary climatic forcing of phytoplankton at basin scale}

Decadal scale changes within phytoplankton communities in the Atlantic and North Sea were originally identified by [2]. They suggested that these were climatically driven with the spreading of unusually cold waters from the Arctic resulting in the decline in phytoplankton north of $59^{\circ} \mathrm{N}$. Further south, phytoplankton increased in their season length and abundance. They suggested that changes in the North Atlantic Oscillation altered the centre of deep-water convection from the Greenland Sea to the Labrador Sea after 1988. The likely sources of these colder waters are stronger westerlies with a larger export of fresh water from melted ice around the Arctic Sea. These results provided the first suggestion that phytoplankton may be responding to climatic forcing on decadal scales. Since then further analysis of new data obtained showed that presence of a regime shift in the phytoplankton in the North Sea with an inflection point in the late 1970's (Fig. 1). 


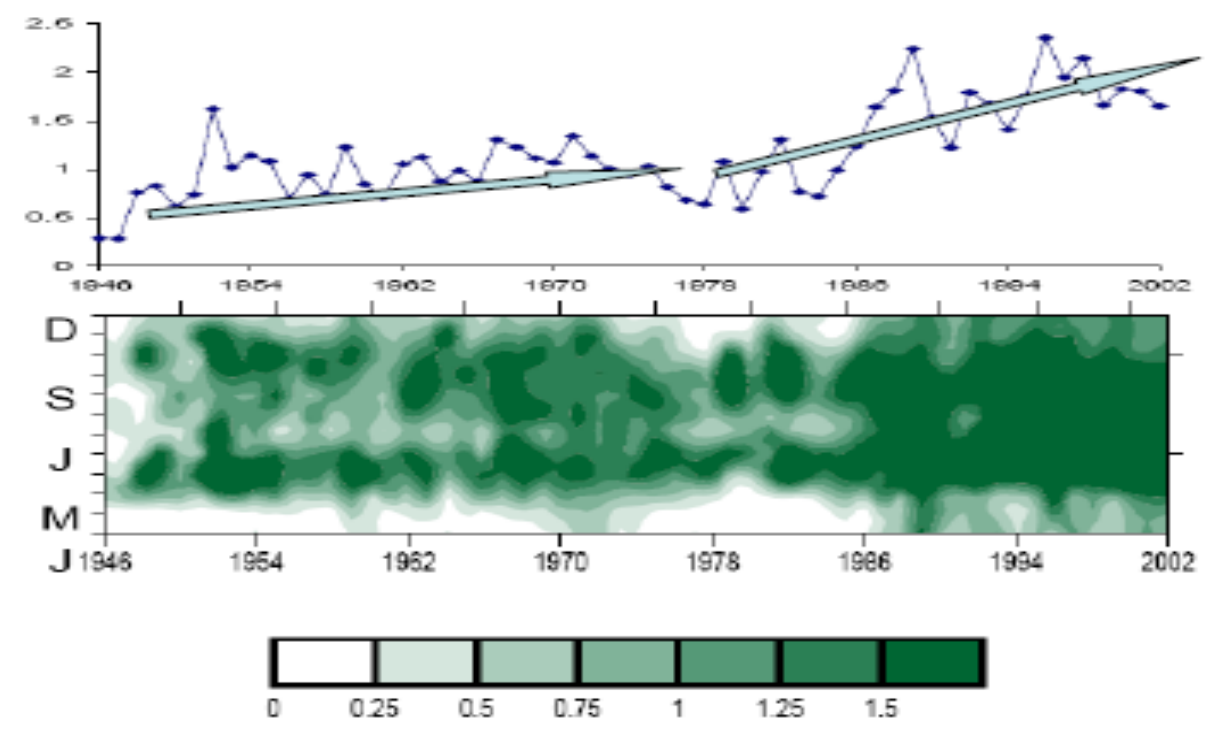

Figure 1: Long term monitoring of phytoplankton in the North Sea demonstrated a clear regime shift in the late 1970s. The new regime was characterised by a higher rate of increase of phytoplankton and extended growth period. The upper panel shows phytoplankton chlorophyll concentration in ug/l. The lower panel shows monthly results over a period of some 60 years. Updated from [2].

\subsection{Continuous change of Atlantic plankton biodiversity}

A biogeographical analysis of zooplankton in the eastern North Atlantic revealed that calanoid copepods were distributed as 5 separate communities with distinct taxonomic groupings. Large-scale changes in the distribution of these communities in the eastern North Atlantic Ocean and European shelf seas were shown by [3]. Strong biogeographical shifts in all copepod assemblages occurred with a northward extension of more than 10 degrees latitude of warm-water species associated with a decrease in the number of colderwater species. These biogeographical shifts agreed with changes in the spatial distribution and phenology detected for many taxonomic groups in terrestrial European ecosystems. The shifts are related to both the increasing trend in Northern Hemisphere temperature and the North Atlantic Oscillation (Fig. 2).

\subsection{New biological coupling of Pacific and Atlantic Oceans}

In 1999, the CPR survey revealed large numbers of the Pacific diatom Neodenticula seminae in the Labrador Sea [4]. This was the first occurrence of this species in the North Atlantic for more than 800,000 years (Fig. 3).
The arrival coincided with modifications in Arctic hydrography and circulation, increased flows of Pacific water into the Northwest Atlantic and the exceptional occurrence of extensive ice-free water to the North of Canada in the previous year. These observations suggest that $N$. seminae was carried in a pulse of Pacific water in either 1998 or 1999 via the Canadian Arctic Archipelago. The species occurred previously in the North Atlantic during the Pleistocene from $\sim 1.2$ to $\sim 0.8 \mathrm{Ma}$ as recorded in deep sea sediment cores. The reappearance of $N$. seminae in the North Atlantic is an indicator of the scale and speed of changes that are occurring in the Arctic and North Atlantic oceans as a consequence of regional climate warming. Because of the unusual nature of the event, it appears that a threshold has been passed, marking a change in the circulation between the North Pacific and North Atlantic Oceans via the Arctic. Trans-Arctic migrations from the Pacific into the Atlantic are likely to occur increasingly over the next 100 years if Arctic ice continues to melt. The invasion by a single species is remarkable enough but the real significance of this is that a physical barrier has been breached between the two oceans [5]. If viable pathways through the Arctic result in more Pacific species following, this might pose a threat to native Atlantic species through competition 

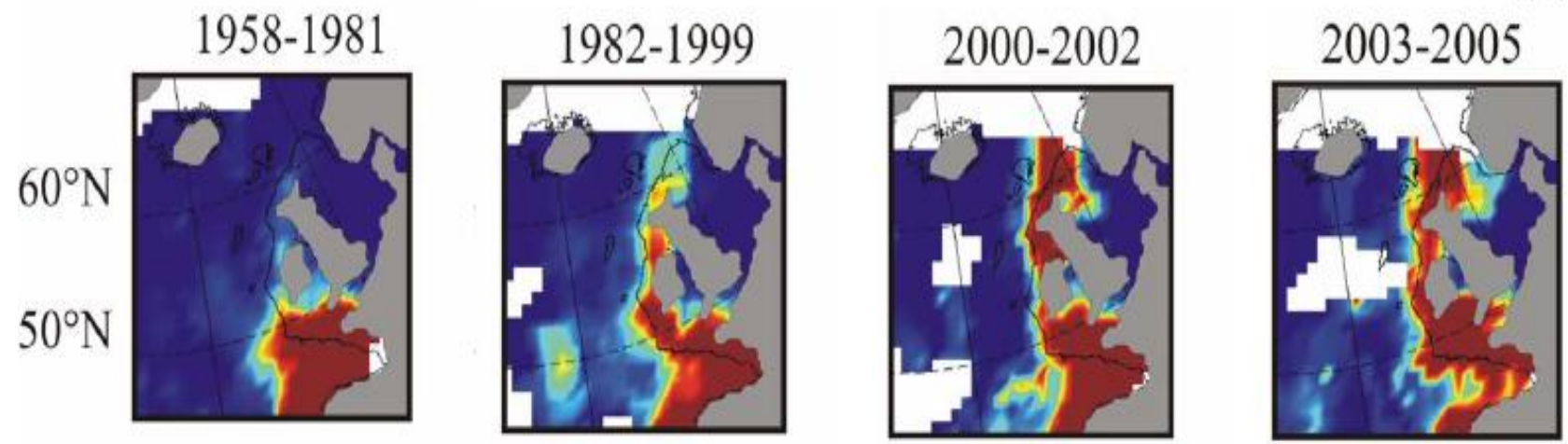

\section{Sub Arctic species}
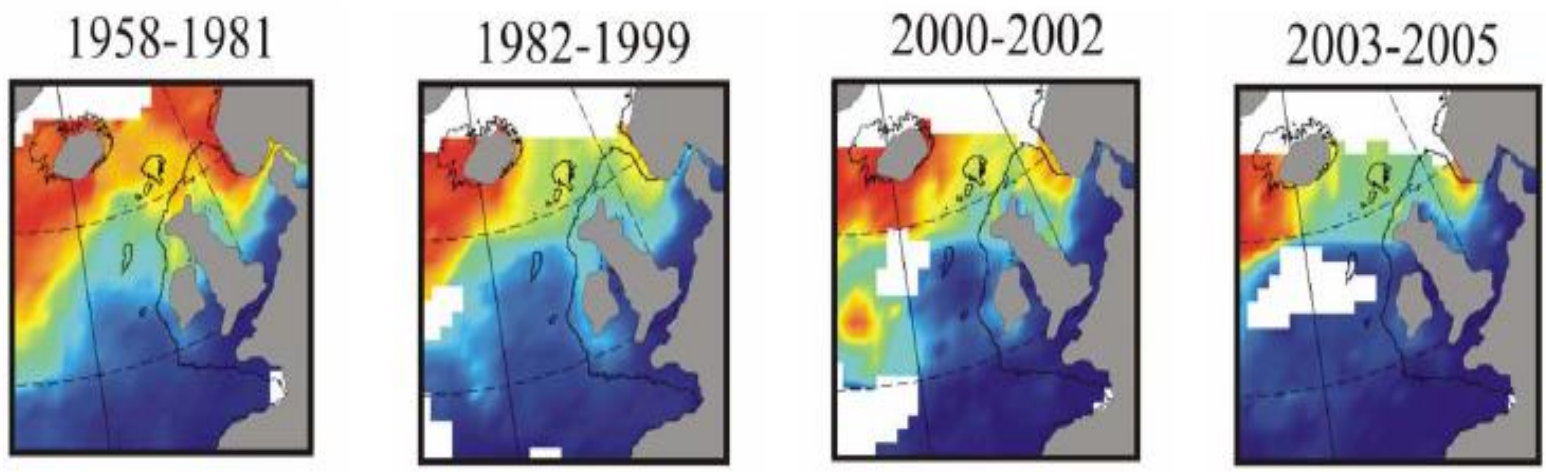

Figure 2: Decadal scale changes in the distribution of the warm temperate and sub-arctic communities of plankton in the eastern North Atlantic water. Over the 5 decades both communities have moved northwards by $>10^{\circ}$ of latitude. Updated from [3].

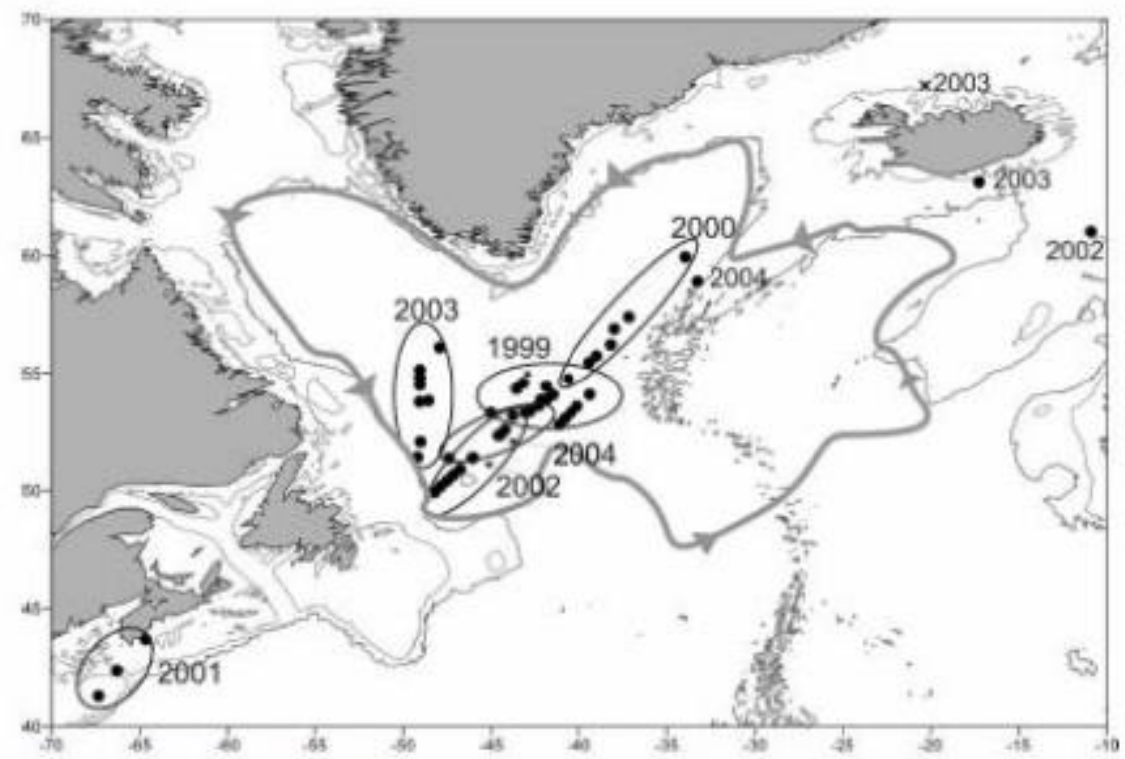

Figure 3: Distribution of the Pacific diatom, Neodenticula seminae, in the Atlantic since it was first recorded there in 1999. (Redrawn from [4]. 
for resources, transformation of the plankton ecosystem and potentially alteration of biogeochemical processes associated with the biological pump. Another phytoplankton Coscinodiscus wailesii, previously invaded the North Sea from the Indian and Pacific Oceans. This diatom displaced indigenous species under certain conditions. It was also found to be unpalatable by some phytophagous species suggesting there may be further effects within the marine foodweb.

\subsection{What are the consequences of regime shifts?}

One of the many questions posed by changes to biodiversity- given that the biological changes are species dependent, are all species within a community equally susceptible to change? Is community reassembly a natural consequence of climatic change? Will community function alter with climate change? Will there be an imbalance in system trophodynamics? In some systems, regime shifts [6] have been documented. These are characterized by large scale abrupt changes in the ecosystem with major biological modifications. Regime shifts remain poorly understood, and may not be recognised until long after they had actually occurred [6].

\subsection{Forecasting future plankton regimes.}

Recent studies have shown that plankton in the North Atlantic differ in their sensitivity to temperature change [7]. The Atlantic ecosystem has a critical thermal boundary at $\sim 10^{\circ} \mathrm{C}$ across which small temperature changes trigger abrupt community shifts. Furthermore, this thermal boundary seems to be a conservative feature of the pelagic ecosystem since it influences phytoplankton, zooplankton and fish (Fig. 4).
This is a significant step forward in understanding climatically driven regime shifts at macroscales. Changes in biodiversity and in the ecosystem function are essential to understanding fish stocks that are already under pressure from fishing. Although mechanistic details remain to be determined, the identification of the $10^{\circ} \mathrm{C}$ isotherm as a critical boundary, offers an approach to project future changes in the North Atlantic ecosystem. This is an important tool for policy makers for regional and basin scale ecosystem management. The study also offers a broader insight to regime shifts since the regions in which a biome boundary shift occurs appear to be the areas most vulnerable to climate change impacts in the North Atlantic. Other regions embedded within a major biome can remain relatively ecologically stable over long periods. With the speed and magnitude of climate warming is expected to be elevated [8], abrupt ecosystem shifts will probably accelerate with consequences for fishing. Monitoring of rising variance in biodiversity gives an early warning for ecosystem managers of an impending abrupt shift. The study suggests the paradigm of relative stability of marine ecosystems should be abandoned and that a proactive, dynamic and flexible management strategy, based on a large-scale ecosystem approach and regular monitoring of plankton biodiversity, should be adopted.

\section{GOING GLOBAL - THE FUTURE EVOLUTION OF CPR SURVEYS.}

CPR Surveys address a global challenge - identifying how and why plankton communities are changing as well as what the consequences of such changes are. This challenge requires a global perspective. Fortunately a 
(a)
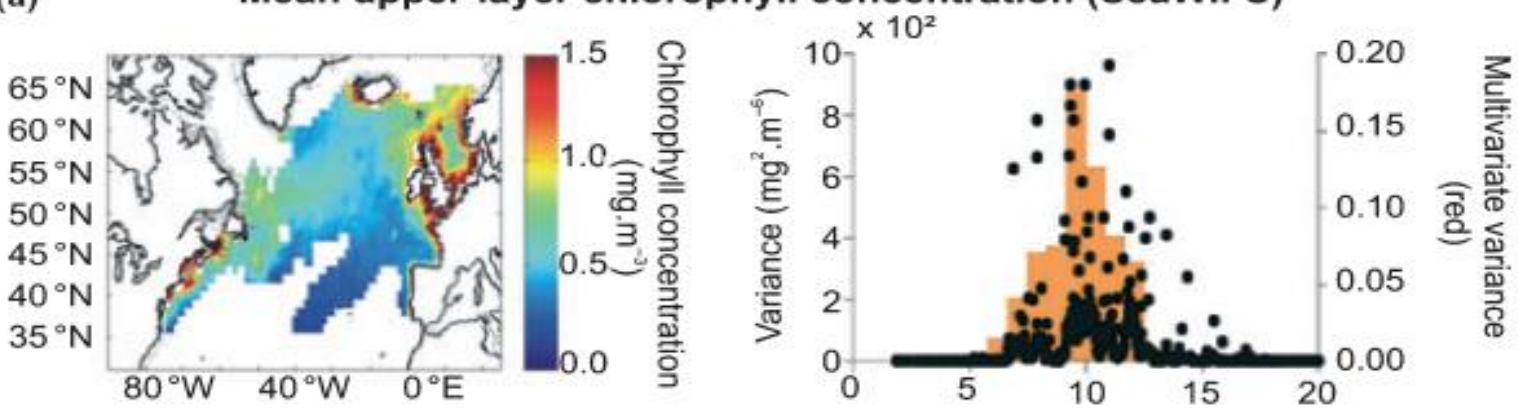

(b)
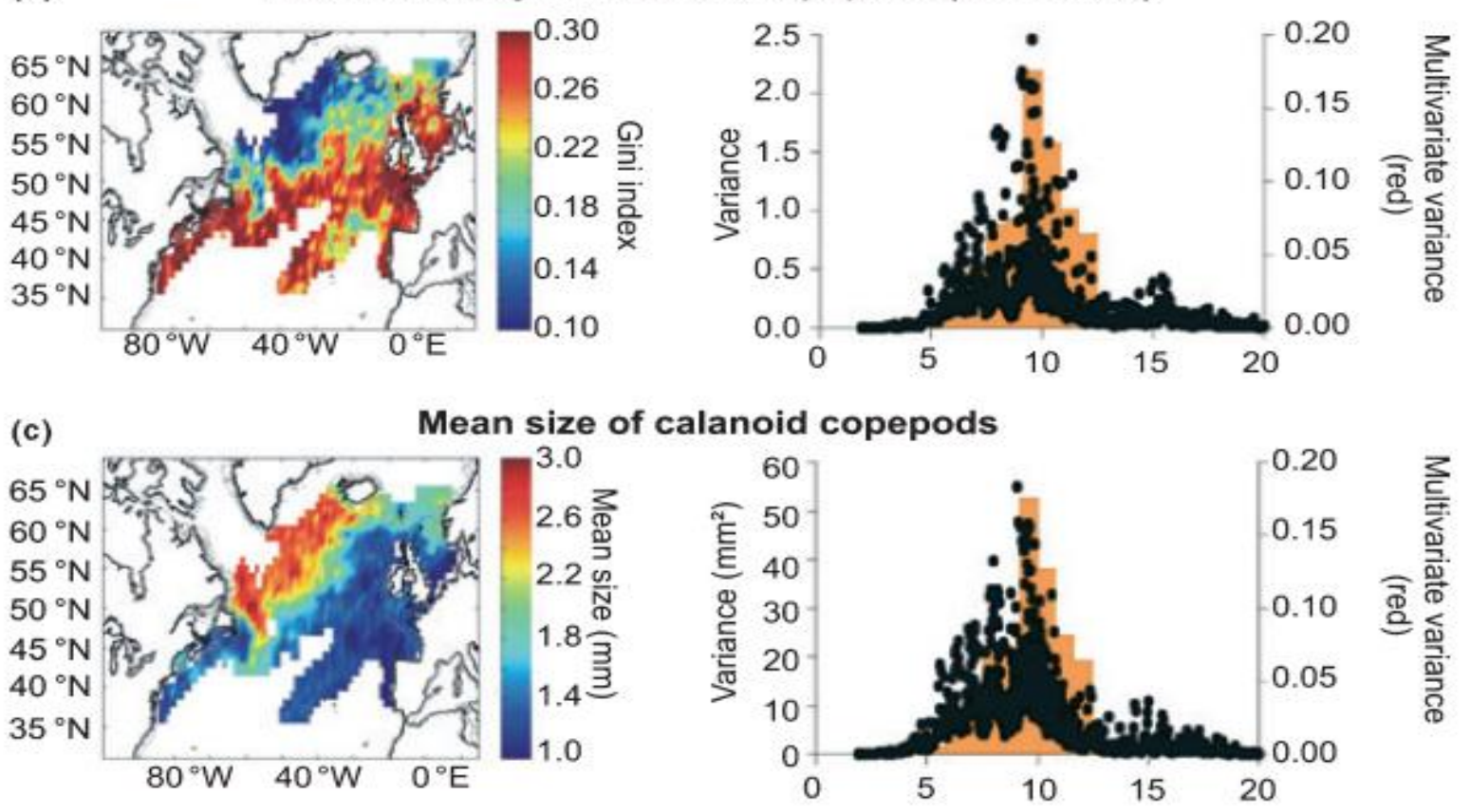

(d)
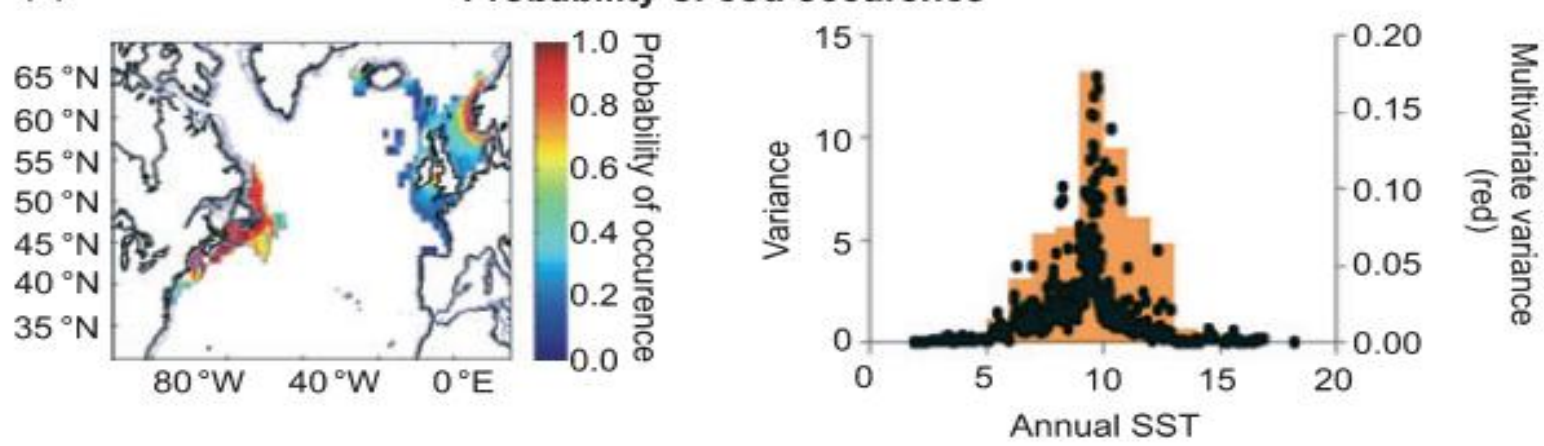

Figure 4. Climatological annual mean distribution of upper-ocean chlorophyll concentration as measured by SeaWIFS (Sea-viewing Wide Field of View Sensor) (a, left; 1997-2006); diversity (Gini index; 1958-2005) of calanoid copepods as measured by the CPR survey (b, left); mean size of female calanoid copepods (c, left; 1958-2005), mean probability of cod occurrence (d, left) and the local variance of these biological parameters as a function of sea surface temperature (right). Each point denotes a geographical pixel on the map. High values of local biological variance are mainly detected between 9 and $12^{\circ} \mathrm{C}$ with a maximum between 9 and $10^{\circ} \mathrm{C}$, indicating substantial variability in these

functional attributes in regions with a temperature regime of $9-10^{\circ} \mathrm{C}$. Red bars, showing the assessment of the (multivariate) variance when all three indicators are combined, confirmed that high values of variance are located between 9 and $10^{\circ} \mathrm{C}$. Grey lines denote the isobath $200 \mathrm{~m}$. Redrawn from [7]). 
number of regional CPR surveys based in USA (United States of America), Australia, New Zealand as well as UK (United Kingdom) are now established and more surveys are starting each year. However each survey currently works independently and it is now timely to build a more cohesive structure. The aim is now to generate a commonwealth of surveys linked with common objectives with the ability to pool knowledge and experience, cemented through common international standards of sampling, analysis, quality control, data processing and sample and data storage. Such an ocean-wide network of CPR surveys should interface with other biological, chemical and physical sampling and analysing technologies as part of regional integrated marine observing programmes. Further details are identified in [9].

Such a step is essential if coordinated plankton monitoring system at basin scale is to be achieved. There are increasing imperatives to achieve this. Within Europe, there is an opportunity to achieve this through the advent of the Marine Strategy Framework Directive which will require all nations to demonstrate "good environmental status" targets for biological diversity, non-indigenous species, status of fish stocks and of the marine food web, eutrophication, marine litter as well as indicators. These need to be developed for each European regional sea by 2012 and a monitoring programme established by 2014 that includes measurements of phytoplankton and zooplankton.

As global fisheries come under increasing pressure there is an urgent need to understand the "natural rules" that underpin fish sustainability. The long overdue recognition of an ecosystem approach to fisheries management requires understanding of the resources that fish require to grow and develop. This includes their food and all utilise fish stocks require plankton at some stage of their lives.

Understanding climate change requires, again at the basin scale, data on key variables that influence climate. Plankton is the biological pump and an understanding of the activity of these complex biogeochemical processes are now needed on the global scale. The impact of climate on marine ecosystems is also paramount and as has been shown above, the results from the CPR survey provided some of the most convincing evidence for this for IPCC (Intergovernmental Panel on Climate Change) Fourth Assessment Report [8].

\section{ACKNOWLEDGMENTS}

We thank all past and present members and supporters of the Sir Alister Hardy Foundation for Ocean Science whose sustained help has allowed the establishment and maintenance of the CPR data-set in the long-term. Consortium support for the CPR survey is provided by agencies from the following countries: UK (NERC (Natural Environment Research Council) \& Defra (Department for Environment, Food \& Rural Affairs)), USA, Canada, Faroe Islands, France, Ireland, the Netherlands, Portugal, the IOC (Intergovernmental Oceanographic Commission) and the European Union. We thank the owners, masters and crews of the ships that tow the CPR's on a voluntary basis.

\section{REFERENCES}

1. Field C, Behrenfeld M, Randerson J \& Falkowski, P. (1998) Primary production of the Biosphere: Integrating

Terrestrial and Oceanic Components. Science 281: 237 240

2. Reid P, Edwards M, Hunt H \& Warner A. (1998). Phytoplankton change in the North Atlantic. Nature 391, 546.

3. Beaugrand G, Reid P, Ibanez F, Lindley J \& Edwards M. (2002). Reorganisation of North Atlantic marine copepod biodiversity and climate. Science, 296, 1692-1694.

4. Reid P, Johns D, Edwards M, Starr M, Poulin M \& Snoejis P. (2007) A biological consequence of reducing Arctic ice cover: arrival of the Pacific diatom Neodenticula seminae in the North Atlantic for the first time in 800000 years. Global Change Biology 13, 1910-1921.

5. Corbyn Z. (2007). Atlantic invaders. Nature Reports Climate Change 6: 82-24

6. Reid P, De Borges M. \& Svendsen E. (2001). "A regime shift in the North Sea circa 1988 linked to changes in the North Sea horse mackerel fishery." Fisheries Research 50(1/2): 163-171.

7. Beaugrand G, Edwards M, Brander K, Luczak C \& Ibanez F. (2008) Causes and projections of abrupt climate-driven ecosystem shifts in the North Atlantic. Ecology Letters 111: $1157-1168$

8. Intergovernmental Panel on Climate Change, WGI (2007). Climate Change 2007: Impacts, Adaptation and Vulnerability. Cambridge University Press, Cambridge.

9. Reid, P. \& Co-Authors (2010). "A Global Continuous Plankton Recorder Programme" in these proceedings (Vol. 2), doi:10.5270/OceanObs09.cwp.73 